\title{
The Significance of Reciprocal and Unilateral Friendships for Peer Victimization in Adolescence
}

\author{
Ron H. J. Scholte · Geertjan Overbeek · Giovanni ten Brink • \\ Els Rommes - Raymond A. T. de Kemp • Luc Goossens · \\ Rutger C. M. E. Engels
}

Received: 14 January 2008/Accepted: 11 March 2008/Published online: 25 March 2008

(C) The Author(s) 2008

\begin{abstract}
The present study examined to what extent the number of friends and their social and personal characteristics were related to peer victimization in adolescence. Participants were 2,180 adolescents (1,143 girls), aged 11-18 $(M=14.2)$, who were classified as victims, bullyvictims, or non-involved (i.e., adolescents who neither bullied others nor were victimized by others). Three types of friends were distinguished: reciprocal friends, desired friends (who were unilaterally nominated by a target adolescent) and choosing friends (who unilaterally nominated a target adolescent). Between-group comparisons of the three types of friends showed that victims had fewer reciprocal and choosing friends than non-involved adolescents. Compared to bully-victims and non-involved adolescents, victims had reciprocal friends who were socially less well adjusted. No differences existed with respect to the characteristics of the desired friends. In general, victims' choosing friends scored less positive on the personal characteristics than bullyvictims' and non-involved adolescents' choosing friends. Within-group comparisons revealed that victims' reciprocal friends showed lower adjustment than victims' desired friends, but higher adjustment than their choosing friends.
\end{abstract}

R. H. J. Scholte $(\square) \cdot$ G. Overbeek · E. Rommes ·

R. A. T. de Kemp · R. C. M. E. Engels

Behavioral Science Institute, Radboud University of Nijmegen,

Montessorilaan 3, P.O. Box 9104, 6500 HE Nijmegen,

The Netherlands

e-mail: r.scholte@pwo.ru.nl

G. ten Brink

Research Technical Support Group, Radboud University

Nijmegen, Nijmegen, The Netherlands

L. Goossens

Center for Developmental Psychology, Catholic University

Leuven, Leuven, Belgium
For bully-victims and non-involved adolescents, such differences between their three types of friends were largely absent. Our findings seem to suggest that victims' reciprocal friendships may not be totally default associations and that out of all possible friends, victims might tend to select those who score most positive on personal or social factors.

Keywords Victimization - Bullying · Adolescence . Friendships

Bullying in school is a major problem that affects many children, with prevalence rates ranging from 5 to $26 \%$ in Western and Non-Western countries (Eslea et al. 2003; Smith et al. 1999). During the last decade, bullying is increasingly viewed as a social group phenomenon, and the role of friends has become an important focus of attention. Although the role of friends in relation to victimization has been addressed in a number of studies, our knowledge of the significance of the friendship context is still limited. One of the reasons is that previous research has primarily focused on reciprocal friendships. The general aim of the present study was to explore how friendships were related to victimization, acknowledging that in order to better understand the role of friends, not only reciprocal but also unilateral friendships should be examined.

Research shows that two aspects are important in order to understand the significance of friendships in relation to victimization. First, studies on the number of friends suggest that children who have at least one (Boulton et al. 1999; Hodges et al. 1999; Pellegrini et al. 1999) or more (Pellegrini and Long 2002; Schwartz et al. 2000) reciprocated best friends in their class are less likely to be victimized. Second, the characteristics of the friends may be important indicators of their potential to protect against 
victimization, with some friends being more able to protect than others. Children who have friends who lack physical strength, suffer from internalizing behaviors, or who are less accepted, are more likely to be victimized (e.g., Güroğlu et al. 2007; Hodges et al. 1997; Hodges and Perry 1999). In contrast, having a bully as a friend is related to lower risk for victimization (Pellegrini et al. 1999). However, although previous research has been informative about the association between friendship and victimization, it has focused exclusively on reciprocal friendships (i.e., two members of a dyad reciprocally choosing the other as a friend) but has neglected the role of the so-called unilateral friends. ${ }^{1}$ Two types of unilateral friends can be distinguished. Desired friends (cf. Aloise-Young et al. 1994) consist of those peers who are nominated as a friend by a target individual but who do not consider that target individual as their friend. Choosing friends, on the other hand, are those peers who choose the target individual as a friend but whom the target individual in return does not regard as his or her friends. Desired and choosing friends represent important aspects of the friendship context and may be crucial for understanding the significance of friendships with respect to victimization.

Information about victims' desired friends is important because it can reveal whether victims actually contribute to their own victimization by the friends they desire and ultimately choose as friends. When victims select friends who are victimized themselves and who are socially less skilled, they may not experience the positive social interactions important to the growth of social knowledge and social skills. Consequently, they may become increasingly unlikely to respond adequately in specific social situations, amplifying the risk for being targeted by bullies. Recent studies seem to support this idea. For example, victims may to a certain extent contribute to the very environments that may cause them to be victimized, because they have friends who are similar to them in terms of risk factors such as particular social characteristics (e.g., victimization, social acceptance) and personal characteristics such as physical weakness, internalizing problems (Hodges et al. 1997). This similarity may stem from different processes, including friend selection. It is believed that the reason why victims may have friends who are like them, even at the risk of continued victimization, can be found in the human tendency to select friends who are similar to one

\footnotetext{
${ }^{1}$ Although some scholars (e.g., Hartup 1996) argue that friendships consist of two dyad members who mutually see each other as friends (i.e., reciprocal friends), other studies define friendship as a dyadic relationship in which one member perceives the other as friend irrespective of whether this friendship choice is reciprocated (Newcomb and Bagwell 1995). In the present study we adhere to this conceptualization and therefore speak of friendship also when a friendship nomination is not reciprocated and is thus unilateral.
}

self, as is suggested by the homophily or similarity hypothesis (Hogue and Steinberg 1995; Kandel 1978). The underlying assumption here is that similarity in social and personal characteristics is rewarding because it involves cooperation with others who have similar experiences, thoughts, feelings, and views. Thus, similarity is believed to validate one's self-concept and self-worth, while dissimilarity could represent a threat. This is of special importance in adolescence when children are faced with the developmental task of constructing a stable self-concept (Harter 1990). Support for the similarity hypothesis comes from studies that show that reciprocal friends are similar to one another in behavior and attitudes (Hogue and Steinberg 1995; Haselager et al. 1998). Although these studies were exclusively based on reciprocal friendships, it can be assumed that this similarity mechanism guides a victim in the selection of all of his or her friends. Consequently, it can be expected that victims' reciprocal friends and also their desired friends may resemble them on a range of social and personal characteristics, because both types of friends are selected by the victims. An alternative hypothesis would be that victims want to have friends who are normally adjusted. According to this "normalcy hypothesis" it could be expected that victims' select friends who are dissimilar to them in that these friends will show a more positive profile on social and personal characteristics.

Choosing friends (i.e., peers who choose a victim as a friend but who are not chosen by that victim) may also be important for our understanding of the significance of the friendship context in relation to victimization. It is likely that peers who consider themselves friends of a victim, thus reciprocal and choosing friends alike, tend to spend time and interact with that victim. They can also be expected to somehow try to defend or help when the victim is harassed. Since classmates are highly aware who interacts and affiliates with whom (Cairns et al. 1988), everyone in class, including bullies, will notice who is around the victim and might be willing to protect him or her. The number and characteristics of these choosing friends may signal to a bully the impact of the reactions his or her bullying behavior may provoke in those who consider themselves friends of the victimized peer. Even if these friends are not highly socially accepted, a higher number of them may pose a threat to the social status of the bully because of their more general disapproval of the bully's behavior. Some studies suggest that, in general, the characteristics of the choosing friends are not associated with an individual's characteristics (Mrug et al. 2004). However, whether this also holds for victims' choosing friends is currently unknown and we can only speculate whether the number of this type of friends and their characteristics are related to victimization. 


\section{The Present Study}

The present study explored the associations between friendship and victimization. To assess these associations, we classified adolescents into victims, bully-victims, and non-involved. Although many studies have examined victims as a homogeneous group, recent studies have clarified that a distinction can be made between victims and bullyvictims (Pellegrini 1998). Whereas victims seldom use aggression towards others, bully-victims include individuals who are victimized but also frequently aggress towards peers (Olweus 1993; Pellgrini et al. 1999; Perry et al. 1990). Because of their dual involvement, they may be most vulnerable and at highest risk for psychosocial problems because they display the behavioral patterns that are distinctive for bullies and for victims. Indeed, a small number of studies have shown that adolescent bullyvictims display a unique combination of psychosocial risk factors consistent with their bullying and victimization experiences (Austin and Joseph 1996; Haynie et al. 2001; Marini et al. 2006). However, bully-victims do not necessarily demonstrate poorer adjustment than victims on social features that are related to victimization (Marini et al. 2006). It has been found that bully-victims find it less difficult to make friends and tend to have slightly more positive relationships with classmates (Nansel et al. 2001), although other studies suggest that bully-victims are more socially rejected (Perry et al. 1988) and less accepted (Austin and Joseph 1996). To what extent victims and bully-victims differ in their friendships is currently unknown.

We addressed two research questions. The first question was to what extent characteristics of adolescents' reciprocal, desired, and choosing friends were related to victimization. We examined whether the social and personal characteristics of the three types of friends (i.e., reciprocal, desired, choosing) were different for victims', bully-victims', and non-involved adolescents' friends. According to the similarity hypothesis, adolescents select peers as friends who are similar to them in terms of behavior, cognitions, and attitudes. Consequently, we expected to find that victims and bully-victims would nominate friends (i.e. reciprocal or desired friends) who, like themselves, scored relatively high on victimization and rejection, and relatively low on social acceptance, extraversion, emotional stability and self-esteem, and would differ from the reciprocal and desired friends of noninvolved adolescents. Based on the normalcy hypothesis, however, we could expect that victims and bully-victims would select friends who would be normally adjusted, and thus would differ from them on various aspects of social and personal characteristics that have been related to victimization in previous research. Given that no studies or theoretical models existed with respect to the association between the characteristics of choosing friends and victimization, no specific hypotheses were raised about possible differences between victims' and non-involved adolescents' choosing friends.

The second research question we addressed was whether victims' and bully-victims' reciprocal friends were similar to their desired and choosing friends. This question was relevant because it could reveal whether victims and bullyvictims had the kind of friends they actually desired. Comparing victims' and bully-victims' reciprocal friends with their choosing friends made it possible to explore whether victims and bully-victims are likely to have default friendships. Default friendship refers to the social phenomenon that because individuals hold a relatively marginal position in a group, such as being victimized, there is a smaller pool of possible peers to establish friendships with, and that pool is largely limited to peers who hold the same position in the group. This implies that if default friend selection would exist with respect to victimization, we would expect no differences between victims' or bullyvictims' reciprocal and choosing friends. Finding differences, however, might provide some preliminary evidence for the idea that victims tend to select those friends who seem, for example, more normally adjusted. Comparing victims' and bully-victims' reciprocal and desired friends might provide additional information about their friendships being default or not. That is, if no differences would exist between these two types of friends, then this would indicate that their friendships are not likely to be default in any way. However, if we would find that the desired friends are better adjusted than the reciprocal friends, than this would suggest some form of default association, as it indicates that victims and bully-victims do seem to be limited in the pool of potential friends. That is, they may be limited to a range of friends who may be less desirable than the desired friends.

\section{Method}

\section{Participants}

Participants were 1,143 girls and 1,037 boys, aged 11-18, with a mean age of 14.2 years $(M=1.1$ year). The participants came from 129 secondary education school classes spread over 23 schools. As for educational levels, $33 \%$ was enrolled in average or higher-level educational programs and $67 \%$ followed lower or vocational types of secondary education, which is representative of the Dutch situation. The majority of the adolescents were of Dutch origin (87\%), while 5\% came from Turkey or Morocco, $1 \%$ from the Dutch Antilles, Suriname and Aruba, and 7\% from other countries. 


\section{Procedure}

The adolescents were selected using a stratified sampling procedure. First, a total of 41 high schools were sent letters of introduction and were contacted by telephone shortly thereafter. Of these schools, 23 agreed to participate. Reasons why schools did not want to participate were that they were too busy or were already involved in other studies. If a certain school agreed to participate, the research team and school board discussed the number of classes eligible for the assessment. Passive parental consent was obtained from the parents, as adolescents took home letters informing their parents about the study and asking for permission. There were no parents who refused their child to participate.

Trained master students conducted the classroom assessments from January to March 2005. All classroom assessments were performed during regular school hours and lasted no more than $50 \mathrm{~min}$, which was the regular time for one lesson. No explicit refusals from pupils to participate in the study were recorded. In most classes, teachers were present during the assessment in order to help explain the content of certain items. In our instructions to the adolescents, we emphasized the confidentiality of the data and stressed that they should not talk about their answers with their classmates.

\section{Measures}

\section{Victimization}

Before answering the bullying involvement questions, the adolescents were given the following definition of "bullying other children" (Olweus 1989):

It is bullying when an adolescent or a group of adolescents say mean things to another adolescent. It is also bullying when an adolescent is being hit, kicked, threatened, locked in or something, or when he or she is excluded and isolated. It is bullying when these things happen frequently and when it is difficult for the adolescent to defend him or herself. It is NOT bullying when two adolescents who are equally strong quarrel, fight with each other, or tease one another.

\section{Self-Reported Victimization and Bullying}

Self-reported victimization and bullying was assessed using the victim scale of Olweus' Bully-Victim questionnaire (Olweus 1989). The victimization scale consisted of five items (e.g., "how often do classmates say mean things to you") rated on a 5-point scale ( $1=$ 'never', $2=$ 'once a month', $3=$ '2-3 times a month', $4=$ 'once a week', $5=$ 'several times a week'). Cronbach's $\alpha$ reliability was .70. The bullying scale also consisted of five items (e.g., "how often have bullied someone"), with the same answering categories, and contained questions related to bullying. The reliability was .73 .

\section{Reciprocal, Desired, and Choosing Friends}

Adolescents were asked to nominate a maximum of five classmates who were their friends. The program MAKE DYAD (Thissen and Bendemacher 2002) was used to identify all possible reciprocal and unilateral friendship dyads, and neutral dyads (i.e., both dyad members do not nominate one another) in each class. When two classmates mutually nominated one another as friend, they were considered reciprocal friends. If an adolescent nominated a classmate but was not nominated by this classmate, the classmate was considered a desired friend. When an adolescent was nominated by a classmate whom he or she did not nominate, this classmate was regarded a choosing friend.

\section{Peer Nominated Social Acceptance, Social Rejection and Victimization}

Social acceptance and rejection were based on the peer nomination items "Which classmates do you like most" and "Which classmates do you like least". Peer nominated victimization was based on the question "Which classmates in your class are bullied". On each of these items, the participants were asked to nominate up to five classmates; self-nominations were not allowed. For each participant, scores on each of these three items were determined by summing all received nominations from classmates on that item. These three raw scores were transformed into within-class probability scores ( $p$-scores) assuming a generalized binomial distribution, thus correcting for unequal numbers of nominations made among children and differences in class size (Newcomb and Bukowski 1983). The $p$-scores were then $z$-standardized across all participants.

\section{Number of Friends Outside the Class}

Adolescents were asked to write down the number of friends they had outside the class.

\section{Big Five Personality Dimensions}

Adolescents' self-reported personality dimensions were assessed using the Quick Big Five (Vermulst and Gerris 2005). This questionnaire consists of 30 items measured on 
a 7-point scale, representing the Big five dimensions, six items for each dimension. These dimensions were Extraversion (e.g., "talkative", $\alpha=.81$ ), Agreeableness ("friendly", $\alpha=.77$ ), Conscientiousness (e.g., "hard working", $\alpha=83$ ), Emotional Stability ("nervous", $\alpha=.83$ ), and Openness to new experiences (e.g., "creative", $\alpha=.66$ ).

\section{Loneliness}

The Louvain Loneliness Scale for Children and Adolescents (LLCA, Goossens and Marcoen 1999) was used to measure self-reported loneliness in relationships with peers. The scale consisted of 10 items (e.g., "I feel isolated from others"), each with a possible response of 1 ('never'), 2 ('seldom'), 3 ('sometimes'), or 4 ('often'). Cronbach's $\alpha$ was .90.

\section{Self-Esteem}

In order to assess self-esteem we employed the Rosenberg Self-esteem questionnaire (Rosenberg 1979). This scale consisted of 10 items (e.g., "Sometimes I think that I am good at nothing") rated on a 5-point scale, ranging from 1 ('totally disagree') to 5 ('totally agree'). The reliability of the scale was .85 .

\section{Statistical Analyses}

The characteristics of the three types of friends (i.e., reciprocal, desired, choosing), rather than the characteristics of the victims themselves, were analyzed to answer our research questions. When an adolescent had more than one friend of a certain type, the scores of all friends of that type were summed and averaged. Because this method may have been statistically conservative, we repeated the analyses on the dataset in which all friends were counted as a separate dyad, resulting in many more dyads per adolescent. For example, if an adolescent had four reciprocal friends, in the first method the scores of these friends were averaged and the adolescent obtained one score, while in the second method the adolescent obtained four scores. The two methods did not result in different findings.

A complication of analyzing friendship dyads in groups is that the data are often statistically non-independent because individuals can be targets (i.e., who nominate) as well as friends (i.e., who are nominated). As a consequence, the participants are probably included more than once in the analyses. To check whether the results were affected by statistical non-independence, we used a randomization test. Applying a bootstrapping approach, the participants were randomly linked to the dyads in a series of simulations, the (aggregated) dependent variables were recomputed and the $F$-statistic determined. The distribution of the $F$-statistic was estimated under the null hypothesis that there was no relationship between the fixed factor and the dependent variable. By this approach, the actual distribution of the variables and the multiple membership was automatically taken into account. The position of the original $F$-statistic in this distribution was interpreted as the probability used in the decision whether to accept or to reject the null hypothesis. The results of this analysis indicated that it was unlikely that our findings were affected by statistical non-independence.

\section{Results}

Adolescents were classified as victims when they scored +1 $S D$ above the mean on the victim scale and lower than +1 $S D$ on the bully scale. Bully-victims were those adolescents who scored higher than $+1 S D$ on both scales, while noninvolved adolescents consisted of those adolescents who scored lower than $+1 S D$ on both scales. As Solberg and Olweus (2003) show, using a cut-off point of $1 S D$ may be less appropriate to estimate prevalence rates but is very well suited to identify extreme groups of victims whose behavior profile can be studied. Our classification resulted in $251(10 \%)$ victims, $76(3 \%)$ bully-victims, and 1,853 (76\%) non-involved adolescents. Adolescents who scored $+1 S D$ on bullying and lower than $+1 S D$ on victimization were dropped from further analyses since they represented the bullies ( $n=263,11 \%$ of the original sample), while our study focused on victims and used the non-involved adolescents as the control group. The prevalence rates of victims, bully-victims, and non-involved adolescents in our study are comparable to prevalence rates reported in other studies (e.g., Eslea et al. 2003; Nansel et al. 2001; Salmivalli and Nieminen 2002).

Preliminary analyses showed that girls were less often a bully-victim than boys $\left(\chi^{2}=11.25, p<.01\right)$. Chi-square analyses revealed that victims were more likely than bullyvictims and non-involved adolescents to have no reciprocal friends $\left(\chi^{2}=11.12, p<.01\right)$ or no choosing friends $\left(\chi^{2}=16.05, p<.001\right)$ in class. No significant differences existed between the three groups in having zero versus one or more desired friends in class $\left(\chi^{2}=2.67\right.$, n.s. $)$.

To further examine whether victims, bully-victims, and non-involved adolescents themselves differed from each other on social characteristics and personal characteristics, we used 3 (victim, bully-victim, non-victim) by 2 (girls versus boys) analyses of variance (MANOVA). The results are presented in Table 1. A multivariate effect was found for the numbers of friends (Wilks' $\Lambda=.979, F(3,4320)=7.73, p<.001$. Post hoc tests indicated that victims had fewer reciprocal and choosing friends than non-involved adolescents, but had the same number of desired friends. Bully-victims differed 
Table 1 Social and personal characteristics of victims, bullyvictims, and non-involved adolescents
Note: $(z)$ : Standard scores; in boldface the $F$-values of the multivariate analyses. Means with different superscripts in the same row are significantly different at $p<.05$

$* p<.05 ; * * p<.01$ $* * * p<.001$

\begin{tabular}{|c|c|c|c|c|}
\hline & $\begin{array}{l}\text { Victims } \\
(N=251)\end{array}$ & $\begin{array}{l}\text { Bully-victims } \\
(N=76)\end{array}$ & $\begin{array}{l}\text { Non-involved } \\
(N=1,853)\end{array}$ & $F$-value \\
\hline Numbers of friends & & & & $7.73 * * *$ \\
\hline Reciprocal friends & $1.58^{\mathrm{b}}$ & $1.79^{\mathrm{ab}}$ & $2.04^{\mathrm{a}}$ & $12.24 * * *$ \\
\hline Desired friends & 1.48 & 1.64 & 1.45 & .66 \\
\hline Choosing friends & $.91^{\mathrm{b}}$ & $.97^{\mathrm{ab}}$ & $1.22^{\mathrm{a}}$ & $7.35 * *$ \\
\hline Social factors & & & & $22.93 * * *$ \\
\hline Social acceptance $(z)$ & $-.46^{\mathrm{b}}$ & $.02^{\mathrm{a}}$ & $.11^{\mathrm{a}}$ & $29.94 * * *$ \\
\hline Social rejection $(z)$ & $.57^{\mathrm{a}}$ & $.27^{\mathrm{b}}$ & $-.07^{\mathrm{c}}$ & $35.87 * * *$ \\
\hline No. of friends outside class & $7.08^{\mathrm{b}}$ & $8.53^{\mathrm{ab}}$ & $8.59^{\mathrm{a}}$ & $3.68 *$ \\
\hline Personal factors & & & & $25.14 * * *$ \\
\hline Extraversion & $4.30^{\mathrm{b}}$ & $4.95^{\mathrm{a}}$ & $4.90^{\mathrm{a}}$ & $26.53 * * *$ \\
\hline Agreeableness & $5.41^{\mathrm{a}}$ & $5.17^{\mathrm{b}}$ & $5.53^{\mathrm{a}}$ & $6.07 * *$ \\
\hline Conscientiousness & $4.32^{\mathrm{a}}$ & $3.85^{\mathrm{b}}$ & $4.37^{\mathrm{a}}$ & $3.45^{*}$ \\
\hline Emotional stability & $3.80^{\mathrm{b}}$ & $4.25^{\mathrm{a}}$ & $4.50^{\mathrm{a}}$ & $44.49 * * *$ \\
\hline $\begin{array}{l}\text { Openness to new } \\
\text { experiences }\end{array}$ & 4.60 & 4.41 & 4.63 & 1.11 \\
\hline Self-esteem & $2.81^{\mathrm{c}}$ & $2.96^{\mathrm{b}}$ & $3.17^{\mathrm{a}}$ & $43.88 * * *$ \\
\hline Loneliness & $2.02^{\mathrm{a}}$ & $1.79^{\mathrm{b}}$ & $1.41^{\mathrm{c}}$ & 163.91 *** \\
\hline
\end{tabular}

neither from the victims nor from the non-involved adolescents on any number of friends. With respect to the social factors, a multivariate effect was also found, Wilks' $\Lambda=.939, F(6,4320)=22.93, p<.001$. Univariate analyses showed that the victims were less accepted and more rejected than the bully-victims and non-involved adolescents (see Table 1) and that bully-victims were similar in social acceptance but scored higher on social rejection than noninvolved adolescents. Victims reported having fewer friends outside the school than non-involved adolescents. Differences also existed on most of the self-reported personal factors, Wilks' $\Lambda=.840, F(14,3874)=25.14, p<.001$. The subsequent univariate analyses revealed that victims scored lower on extraversion, emotional stability, and self-esteem, and higher on loneliness than bully-victims and non-involved adolescents. Bully-victims scored lowest on agreeableness and conscientiousness.

\section{Characteristics of Friends in Relation to Victimization}

The first research question we addressed was to what extent friend characteristics were related to victimization. To answer this question, we compared victims' and bullyvictims' reciprocal, desired, and choosing friends with the three types of non-involved adolescents' friends. Analyses of variance (MANOVA) were used with victim status and gender as factors and the social and personal variables as dependent variables.

As Table 2 shows, a multivariate effect was found for victim status on the social factors, Wilks' $\Lambda=.964$, $F(4,1837)=8.70, p<.001$. Subsequent univariate analyses showed that victims' reciprocal friends showed a poorer social adjustment than reciprocal friends of bullyvictims and non-involved adolescents. They were less accepted and more victimized according to the peers, and reported a lower number of friends outside the class context. Bully-victims' reciprocal friends did not seem to differ from non-involved adolescents' reciprocal friends. A multivariate effect (Wilks' $\Lambda=.977, F(14,3572)=3.01$, $p<.001)$ was also found for the personal factors. The univariate analyses showed that victims' reciprocal friends scored lower on extraversion and higher on loneliness than non-involved adolescents' reciprocal friends while bullyvictims' reciprocal friends scored lower on openness and self-esteem than non-involved adolescents' reciprocal friends. However, differences between victims' and bullyvictims' reciprocal friends were found on openness and self-esteem, on which bully-victims' friends scored lowest, while victims' friends did not differ from non-involved adolescents' friends. Significant interaction effects between victim status and sex were not found in the analyses on the reciprocal friends.

Next, victims' desired friends were compared with the non-involved adolescents' desired friends (Table 3). The major finding was that there were no significant main or interaction effects for victim status and thus that no differences existed between victims', bully-victims', and noninvolved adolescents' desired friends, neither on the social nor on the personal characteristics. This finding may have important implications as it suggests that victims and bullyvictims may want the same kind of friends in terms of social or personal characteristics as non-involved adolescents do. 
Table 2 Social and personal characteristics of reciprocal friends of victims, bullyvictims, and non-involved adolescents

Note: (z): Standard scores; in boldface the $F$-values of the multivariate analyses. Means with different superscripts in the same row are significantly different at $p<.05$

$* p<.05 ; * * p<.01$;

$* * * p<.001$

Table 3 Social and personal characteristics of desired friends of victims, bully-victims, and non-involved adolescents

Note: $(z)$ : standard scores; in boldface the $F$-values of the multivariate analyses

$* p<.05 ; * * p<.01$;

$* * * p<.001$

With respect to the choosing friends (see Table 4), no significant multivariate effect for victim status was found on the social factors (Wilks' $\Lambda=.991, F(8,2738)=$ 1.59 , n.s.). This indicated that the peers who unilaterally chose the victims did not differ from those that unilaterally chose the bully-victims or non-involved adolescents. However, a multivariate effect was found for the personal factors, Wilks' $\Lambda=.984, F(14,2564)=2.40, p<.01$. From the subsequent univariate analyses it became clear that victims' choosing friends reported a less positive personal profile than bully-victims' and non-involved adolescents' choosing friends. Compared to bully-victims' choosing friends, victims' choosing friends were less emotionally stable, had lower self-esteem, and reported more loneliness. The only personal factor on which the choosing friends of bully-victims and non-involved adolescents differed was on openness, on which the latter scored higher. An interaction effect between victim status and sex was not found for the social factors or for the personal factors.

\begin{tabular}{cccc} 
Victims & Bully-victims & Non-involved & $F$-value \\
\hline & & & $\mathbf{8 . 7 0 ^ { * * * }}$ \\
$.07^{\mathrm{b}}$ & $.27^{\mathrm{a}}$ & $.28^{\mathrm{a}}$ & $7.29^{* *}$ \\
-.05 & -.20 & -.14 & 1.81 \\
$.18^{\mathrm{a}}$ & $-.11^{\mathrm{b}}$ & $-.16^{\mathrm{b}}$ & $28.87^{*} * *$ \\
$7.88^{\mathrm{b}}$ & $8.12^{\mathrm{ab}}$ & $9.11^{\mathrm{a}}$ & $3.15^{*}$ \\
& & & $\mathbf{3 . 0 1} * * *$ \\
$4.76^{\mathrm{b}}$ & $4.86^{\mathrm{ab}}$ & $4.95^{\mathrm{a}}$ & $4.80^{* *}$ \\
5.50 & 5.39 & 5.53 & 1.28 \\
4.36 & 4.26 & 4.36 & .17 \\
4.37 & 4.33 & 4.50 & 2.42 \\
$4.71^{\mathrm{a}}$ & $4.42^{\mathrm{b}}$ & $4.64^{\mathrm{a}}$ & $3.33^{*}$ \\
$3.15^{\mathrm{a}}$ & $2.99^{\mathrm{b}}$ & $3.14^{\mathrm{a}}$ & $5.65^{* *}$ \\
$1.54^{\mathrm{a}}$ & $1.53^{\mathrm{ab}}$ & $1.41^{\mathrm{b}}$ & $12.50^{* * *}$
\end{tabular}

Victims $\quad$ Bully-victims $\quad$ Non-involved $\quad F$-value

$\begin{array}{rrrr}.52 & .63 & .53 & \mathbf{. 7 7} \\ -.22 & -.32 & -.18 & .48 \\ -.11 & -.23 & -.16 & 1.04 \\ 9.07 & 7.36 & 9.22 & .65 \\ & & & 1.26 \\ 4.92 & 4.98 & 5.01 & \mathbf{1 . 1 1} \\ 5.45 & 5.57 & 5.46 & 1.17 \\ 4.13 & 4.25 & 4.31 & 1.42 \\ 4.44 & 4.60 & 4.47 & 2.34 \\ 4.56 & 4.54 & 4.62 & .35 \\ 3.10 & 3.18 & 3.10 & .41 \\ 1.47 & 1.37 & 1.44 & .16 \\ \end{array}$

Within-Group Comparison of Victims', Bully-Victims', and Non-Involved Adolescents' Reciprocal, Desired, and Choosing Friends

The second research question we addressed was whether the friends with whom the victims, bully-victims, and noninvolved adolescents had established a reciprocal relationship with differed from the friends they wanted (i.e., desired friends) or who wanted them (i.e., choosing friends). To examine this question, planned within-group comparisons were conducted. That is, we compared the social and personal factors of victims' reciprocal friends with those of victims' desired and choosing friends. The same within-group comparisons were conducted within the bully-victims, and non-involved adolescents groups. The latter was done in order to establish whether differences between types of friends were restricted to victims and bully-victims or were more normative for all adolescents.

The analyses revealed important differences between victims' reciprocal friends and desired friends. Concerning 
Table 4 Social and personal characteristics of choosing friends of victims, bullyvictims, and non-involved adolescents

Note: (z): standard scores; in boldface the $F$-values of the multivariate analyses. Means with different superscripts in the same row are significantly different at $p<.05$

$* p<.05 ; * * p<.01$; $* * * p<.001$

\begin{tabular}{lcccc}
\hline & Victims & Bully-victims & Non-involved & $F$-value \\
\hline Social factors & & & & 1.59 \\
Social acceptance $(z)$ & -.20 & .02 & -.22 & .64 \\
Social rejection $(z)$ & .11 & .02 & .05 & .31 \\
Being victimized $(z)$ & .28 & -.10 & .12 & 2.63 \\
No. of friends outside class & 7.74 & 7.32 & 9.45 & 2.99 \\
Personal factors & & & & $2.40^{* *}$ \\
Extraversion & $4.55^{\mathrm{b}}$ & $4.71^{\mathrm{ab}}$ & $4.81^{\mathrm{a}}$ & $4.11^{*}$ \\
Agreeableness & 5.41 & 5.40 & 5.48 & .61 \\
Conscientiousness & 4.34 & 4.32 & 4.33 & .05 \\
Emotional stability & $4.16^{\mathrm{b}}$ & $4.46^{\mathrm{a}}$ & $4.41^{\mathrm{a}}$ & $5.32^{* *}$ \\
Openness to new experiences & $4.45^{\mathrm{ab}}$ & $4.33^{\mathrm{b}}$ & $4.63^{\mathrm{a}}$ & $6.16^{* *}$ \\
Self-esteem & $2.99^{\mathrm{b}}$ & $3.21^{\mathrm{a}}$ & $3.11^{\mathrm{a}}$ & $4.26^{*}$ \\
Loneliness & $1.64^{\mathrm{a}}$ & $1.52^{\mathrm{b}}$ & $1.51^{\mathrm{b}}$ & $3.35^{*}$ \\
\hline
\end{tabular}

their social characteristics, victims' reciprocal friends were less accepted $(t(339)=5.77, p<.001)$, more rejected $(t(339)=2.30, p<.05)$, and more victimized $(t(339)=3.30, p<.001)$ than victims' desired friends. At the same time they scored higher on conscientiousness $(t(339)=2.18, p<.05)$. Surprisingly, such differences were not found between the reciprocal and desired friends of the non-involved adolescents or the bully-victims. The only difference that existed was on social acceptance, on which the desired friends scored higher than the reciprocal friends, with $t(111)=2.95(p<.01)$ for bully-victims, and $t(2796)=8.87(p<.001)$ for non-involved adolescents.

Comparing victims' reciprocal friends with their choosing friends revealed that the choosing friends scored less positively on a number of social and personal characteristics. They were less accepted $(t(315)=4.98$, $p<.001)$, less extraverted $(t(315)=2.02, p<.05)$, less emotional stable $(t(298)=2.28, p<.05)$, less open to new experiences $(t(298)=2.69, p<.01)$, and had a lower self-esteem $(t(298)=2.89, p<.01)$. A similar comparison between the reciprocal and choosing friends of the bully-victims revealed a quite different pattern. These two types of friends hardly differed from each other, except on self-esteem on which the reciprocal friends scored lower $(t(97)=2.24, p<.05)$. For the non-involved adolescents, it showed that the choosing friends scored lower than the reciprocal friends on social acceptance $(t(2886)=16.02$, $p<.001)$, while reciprocal and choosing friends did not differ on the other variables.

\section{Discussion}

The present study examined the role of the friendship context in relation to victimization. An extension of previous research was that we explored the role of desired and choosing friends, in addition to reciprocal friends.
The first research question we addressed was whether these three types of friends differed for victims, bullyvictims, and non-involved adolescents in terms of psychosocial adjustment. The second question was whether the reciprocal friends of victims, and bully-victims, differed from their desired and choosing friends, and whether similar differences also existed for non-involved adolescents.

With respect to reciprocal friends, the findings revealed that victims were more likely than bully-victims and noninvolved adolescents to have zero reciprocal best friends in class. This finding is in line with findings from other studies (Boulton et al. 1999; Hodges et al. 1997, 1999). In addition, victims turned out to have fewer reciprocal friends than non-involved adolescents, while bully-victims did not differ from these two groups. It seems likely that the number of reciprocal best friends, in addition to having versus not having a best friend, is relevant for victimization, as was suggested in other studies (Pellegrini and Long 2002). Our study further shows that not only the number of reciprocal friends but also the number of choosing friends may be relevant for victimization. An explanation here is that bullies will know quite well which adolescents have large networks of peers who consider themselves to be friends (cf. Cairns et al. 1988) and who might help when a victim is attacked. Even if these friends are not powerful individually, together they may exert enough social influence to make a bully refrain from attacking.

Previous studies have reported that victims are likely to have fewer friends outside of school than non-involved adolescents (Smith et al. 2004) or have more difficulties in maintaining friendships (Schäfer et al. 2004). Our study may add to that information as it shows that it is probably true for victims but not for bully-victims. Nevertheless, victims did not report to be friendless in our study. To the contrary, although the number of friends outside of class 
was lower, they still reported a substantial number. This may signal that victims do possess abilities to establish positive peer relations, even if only outside of class. It can also signal that the victimization experiences reported in this study might have been context dependent and were restricted to the school context. Since not much empirical information exists on the cross-context continuity of victimization, more research seems warranted to explore whether some adolescents who are victimized in class do in fact have positive peer relations outside of the school context.

Our study reveals not only that the number of friends is related to victimization, but also that the characteristics of the friends play an important role as well. We found that victims' reciprocal friends were socially less accepted and more victimized, and were more introverted and more lonely than non-involved adolescents' friends. These findings corroborate other studies that show a similarity between victims and their reciprocal friends in terms of victimization and personal resources (Hodges et al. 1997, 1999). Previous studies looked at victims but not at bullyvictims. The differences in friendship contexts of victims and bully-victims found in our study suggest that it is important to differentiate between the two groups of victims. While Hodges et al. (1997, 1999) findings hold for victims, it is not clear whether they apply to bully-victims as well. The findings on the social factors of reciprocal friends in our study highlight that bully-victims tend to have friends who are generally similar to the friends of the majority of adolescents (i.e., non-involved), and that these friends are quite different from victims' friends.

Previous studies on friendships and victimization have focused exclusively on reciprocal friendships. Our study extended this research because we also investigated the characteristics of desired and choosing friends. One relevant question is whether victims have unrealistic goals about the peers they want to be friends with. When victims tend to want friends who score above average on social or personal characteristics, it could have been expected that in our study the victims would have had desired friends that were different from the non-involved adolescents' desired friends. Our results did not support this idea as they showed that victims' desired friends in no way differed from the peers that bully-victims or the non-involved adolescents wanted to have as friends. What our findings support is the idea that what victims may seek in their friendship is normalcy, as they seem to desire socially normally adjusted friends. Thus, their goals in friendships tend to be socially realistic and similar to the goals all other adolescents had, regardless of their victimization status. Of course it could have been possible that the non-involved adolescents too had unrealistic goals and that there is a general tendency in adolescents to nominate those peers as friends who score more positively on social and personal characteristics than oneself. However, the general friendship literature suggests otherwise and has repeatedly found that similarity exists between friends on personal and social characteristics (Haselager et al. 1998; Hogue and Steinberg 1995). Moreover, additional analyses in which we compared the characteristics of the non-involved adolescents themselves (Table 1) with those of their desired friends (Table 3) revealed that they were very similar to the friends they unilaterally chose, except on social acceptance on which the desired friends scored higher.

Comparison of the victims' reciprocal friends with their desired friends showed that the latter scored more positively on a number of salient social aspects: they were socially more accepted, less rejected, and less victimized. Given that victims' reciprocal friends were below average on a number of personal and social characteristics, this finding indicates that victims seemed to want friends who were normally adjusted. For victims, the reciprocal friends and the desired friends seemed to be more promising in this respect than their classmates who unilaterally chose them (i.e., choosing friends). The choosing friends scored less positively both in social and personal domains. The discrepancies between the three types of victims' friends revealed an interesting phenomenon. Of all the peers who were selected by the victims, the ones with the highest social adjustment did not reciprocate the friendship choice. In this respect, there seems to be some kind of social limitation, and a form of default association between victims and their friends, as victims are obviously limited in the pool of potential friends. However, the friendships are not entirely by default, as the victims do have a choice. Of all the peers who chose them, victims only reciprocated the choice of those with the highest social acceptance and most positive personality profile. This phenomenon was more indicative for victims than for bully-victims and noninvolved adolescents because for them the reciprocal and choosing friends hardly differed.

Our findings can add to the knowledge of the friendship choices of victims and bully-victims in relation to victimization. Victims may have a pool of possible friends to choose from and from which they, consciously or unconsciously, select those peers who are normally adjusted. It might mean that a victim does not just establish a reciprocal friendship with any peer who chooses him or her as a friend, but instead makes choices depending on the characteristics of the potential friend. Our findings might imply that victims' reciprocal friendships are not associations totally by default but that they may be based on some kind of selection process. We do not know yet why victims select some peers and deselect others as friends and more research is warranted to examine this issue.

From the present study, we can deduce that victims have a rather broad circle of peers they nominate as friends, as 
indicated by the number of desired and reciprocal friends. The fact that they establish reciprocal friendships with those who score lower on social characteristics may be a matter of non-selection or deselection carried out by the desired friends rather than a deliberate selection by the victims themselves. The desired friends may not be interested in becoming friends with the victims because of the dissimilarity on social and behavioral characteristics (cf. Kandel 1978). Considered this way, victims do not necessarily actively create the very environments that contribute to or reinforce their victimization (cf. Caspi et al. 1989). All in all, our findings might suggest that victims' friendship choice is guided by a "desire-for-normalcy" and that victims can be actively engaged in establishing reciprocal relationships with friends who are normally adjusted. Although these peers may seem less promising in this respect than desired friends, they appear to be more promising than others (i.e., choosing friends).

It is important to note that these findings pertain to the victims, but not to the bully-victims. Our study showed significant differences between victims' and bully-victims' friends. These differences indicate that bully-victims are likely to have a more positive friendship context than victims. Various studies have identified bully-victims as a risk group that may be more problematic than any other group of adolescents, including bullies (Austin and Joseph 1996; Haynie et al. 2001; Pellegrini 1998; Perry et al. 1988). We found that, compared to victims, bully-victims' reciprocal friends showed more positive features on peerreported social factors while their choosing friends showed a more positive profile on the self-reported personal factors. What these findings may suggest is that bully-victims may be able to maintain peer relationships with adolescents who are normally adjusted, as was indicated by the fact that these friends did not differ from the friends of the nonvictimized majority of adolescents. In this respect they differed from the victims, as was also reported in previous studies (Marini et al. 2006).

Our study had a number of limitations that should be acknowledged. First, in the peer nomination procedure we used a restricted range approach allowing the adolescents to only nominate a maximum of five peers as friends. There may have been adolescents who had more friends. However, it is not very likely that this procedure has affected the results substantially. The vast majority of adolescents nominated fewer than five friends $(M=3, S D=1.9)$. Furthermore, in the analyses on the characteristics of the friends, the scores of the friends were summed and averaged, and the addition of friends might not have changed the averaged scores very much. Moreover, we have rerun the analyses using the individual scores of the friends instead of aggregated scores, and the results were identical. Second, the bully-victim group was relatively small $(N=76)$ which may explain the lack of significant differences in a number of comparisons between Tables 2 and 3. Finally, because our study was cross-sectional, all interpretations should be made with caution, and we cannot infer any direction of effects. It is possible that becoming victimized decreases the number of potential friends, and directs an adolescent into the direction of associating with friends who seem to have less social or personal resources. It may be as likely, however, that because an adolescent has fewer friends or has friends with fewer personal or social resources, he or she may become victimized more easily. Clearly longitudinal studies are needed to examine to what extent victimization affects friendship selection or vice versa.

To conclude, our study shows that, in order to understand the role of friendship in relation to victimization, it is important not only to understand reciprocal friends, but also to include choosing and desired friends as well. The study further makes clear that meaningful differences exist between victims and bully-victims in the reciprocal and choosing friends they have. It reveals that bully-victims are likely to have a more positive friendship context than victims. Nevertheless, victims do seem to have some kind of choice in the peers they establish a reciprocal friendship with. Out of all possible friends, they tend to select those who score highest on a number of social and personal characteristics.

Acknowledgement We want to thank two anonymous reviewers for their comments on the first draft of our manuscript.

Open Access This article is distributed under the terms of the Creative Commons Attribution Noncommercial License which permits any noncommercial use, distribution, and reproduction in any medium, provided the original author(s) and source are credited.

\section{References}

Aloise-Young, P. A., Graham, J. W., \& Hansen, W. B. (1994). Peer influence on smoking initiation during early adolescence: A comparison of group members and group outsiders. Journal of Applied Psychology, 79, 281-287.

Austin, S., \& Joseph, S. (1996). Assessment of bully/victim problems in 8 to 11 year olds. British Journal of Educational Psychology, $66,447-456$.

Boulton, M. J., Trueman, M., Chau, C., Whitehand, C., \& Amatya, K. (1999). Concurrent and longitudinal links between friendship and peer victimization: Implications for befriending interventions. Journal of Adolescence, 22, 461-466.

Cairns, R. B., Cairns, B. D., Neckerman, H. J., Gest, S. D., \& Gariepy, J. L. (1988). Social networks and aggressive behavior: Peer support or peer rejection? Developmental Psychology, 24, 815-823.

Caspi, A., Bem, D. J., \& Elder, G. H. (1989). Continuities and consequences of interactional styles across the life course. Journal of Personality, 57, 375-406.

Eslea, M., Menesini, E., Morita, Y., O’Moore, M., Mora-Merchán, J. A., Pereira, B., \& Smith, P. K. (2003). Friendship and loneliness among bullies and victims: Data from seven countries. Aggressive Behavior, 30, 71-83. 
Goossens, L., \& Marcoen, A. (1999). Relationships during adolescence: Constructive vs. negative themes and relational dissatisfaction. Journal of Adolescence, 22, 65-79.

Güroğlu, B., van Lieshout, C. F. M., Haselager, G. J. T., \& Scholte, R. H. J. (2007). Similarity and complementarity of behavioral profiles of friendship types and types of friends: Friendships and psychosocial adjustment. Journal of Research on Adolescence, 17, 357-386.

Harter, S. (1990). Causes, correlates, and the functional role of global self-worth: A life-span perspective. In J. Kolligian \& R. Sternberg (Eds.), Perceptions of competence and incompetence across the life-span (pp. 67-98). New Haven, CT: Yale University Press.

Hartup, W. W. (1996). The company they keep: Friendships and their developmental significance. Child Development, 67, 1-13.

Haselager, G. J. T., Hartup, W. W., van Lieshout, C. F. M., \& RiksenWalraven, J. M. A. (1998). Similarities between friends and nonfriends in middle childhood. Child Development, 69, 11981208.

Haynie, D. L., Nansel, T. R., Eitel, P., Crump, A. D., Saylor, K., Yu, L., \& Simons-Morton, B. (2001). Bullies, victims, and bully/ victims: Distinct groups of at-risk youth. Journal of Early Adolescence, 21, 29-50.

Hodges, E. V. E., Boivin, M., Vitaro, F., \& Bukowski, W. M. (1999). The power of friendship: Protection against an escalating cycle of peer victimization. Developmental Psychology, 35, 94-101.

Hodges, E. V. E., Malone, M. J., \& Perry, D. G. (1997). Individual risk and social risk as interacting determinants of victimization in the peer group. Developmental Psychology, 33, 1032-1039.

Hodges, E. V. E., \& Perry, D. G. (1999). Personal and interpersonal antecedents and consequences of victimization by peers. Journal of Personality and Social Psychology, 76, 677-685.

Hogue, A., \& Steinberg, L. (1995). Homophily of internalized distress in adolescent peer groups. Developmental Psychology, 31, 897-906.

Kandel, D. B. (1978). Similarity in real-life adolescent friendship pairs. Journal of Personality and Social Psychology, 36, 306-312.

Marini, Z. A., Dane, A. W., Bosacki, S. L., \& Ylc-Cura (2006). Direct and indirect bully-victims: Differential psychosocial risk factors associated with adolescents involved in bullying and victimization. Aggressive Behavior, 32, 551-569.

Mrug, S., Hoza, B., \& Bukowski, W. M. (2004). Choosing or being chosen by aggressive-disruptive peers: Do they contribute to children's externalizing and internalizing problems? Journal of Abnormal Child Psychology, 32, 53-65.

Nansel, T. R., Overpeck, M., Pilla, R. S., Ruan, J. W., Simons-Morton, B., \& Scheidt, P. (2001). Bullying behaviors among US youth. Journal of the American Medical Association, 285, 2094-2100.

Newcomb, A. F., \& Bagwell, C. L. (1995). Children's friendship reactions: A meta-analytic review. Psychological Bulletin, 117, 306-347.

Newcomb, A. F., \& Bukowski, W. M. (1983). Social impact and social preference as determinants of children's peer group status. Developmental Psychology, 19, 856-867.

Olweus, D. (1989). The Olweus bully/victim questionnaire. Bergen, Norway: Mimeo.

Olweus, D. (1993). Bullying at school: What we know and what we can do. Malden, MA: Blackwell Publishing.

Pellegrini, A. D. (1998). Bullies and victims in school: A review and call for research. Journal of Applied Developmental Psychology, $19,165-176$

Pellegrini, A. D., Bartini, M., \& Brooks, F. (1999). School bullies, victims, and aggressive victims: Factors relating to group affiliation and victimization in early adolescence. Journal of Educational Psychology, 91, 216-224.

Pellegrini, A. D., \& Long, J. A. (2002). A longitudinal study of bullying, dominance, and victimization during the transition from primary to secondary school. British Journal of Developmental Psychology, 20, 259-280.

Perry, D. G., Kusel, S. J., \& Perry, L. C. (1988). Victims of peer aggression. Developmental Psychology, 24, 807-814.

Perry, D. G., Williard, J. C., \& Perry, L. C. (1990). Peers' perceptions of the consequences that victimized children provide aggressors. Child Development, 61, 1310-1325.

Rosenberg, M. (1979). Conceiving the self. New York: Basic Books.

Salmivalli, C., \& Nieminen, E. (2002). Proactive and reactive aggression among school bullies, victims, and bully-victims. Aggressive Behavior, 28, 30-44.

Schäfer, M., Korn, S., Smith, P. K., Hunter, S. C., Mora-Merchán, J. A., Singer, M. M., \& van der Meulen, K. (2004). Lonely in the crowd: Recollections of bullying. British Journal of Developmental Psychology, 22, 379-394.

Schwartz, D., Dodge, K. A., Pettit, G. S., \& Bates, J. E. (2000). Friendship as a moderating factor in the pathway between early harsh home environment and later victimization in the peer group. Developmental Psychology, 36, 646662.

Smith, P. K., Morita, Y., Junger-Tas, J., Olweus, D., Catalano, R., \& Slee, P. (1999). The nature of school bullying: A cross-national perspective. London, UK: Routledge.

Smith, P. K., Talamelli, L., Cowie, H., Naylor, P., \& Chauhan, P. (2004). Profiles of non-victims, escaped victims, continuing victims and new victims of school bullying. British Journal of Educational Psychology, 74, 565-581.

Solberg, M. E., \& Olweus, D. (2003). Prevalence estimations of school bullying with the Olweus bully/victim questionnaire. Aggressive Behavior, 29, 239-268.

Thissen, M., \& Bendermacher, N. (2002). KUNST MAKEDYAD: Create file of dyads. RTOG-FSW, University of Nijmegen.

Vermulst, A. A., \& Gerris, J. R. M. (2005). QBF: Quick big five personality test manual. Leeuwarden, the Netherlands: LDC Publications.

\section{Author Biographies}

Ron H. J. Scholte is Associate Professor at the Department of Developmental Psychopathology, Radboud University Nijmegen the Netherlands, where he received his Ph.D. in 1998. His areas of interest are social relationships in adolescence, primarily friendships and bullying. In addition, he conducts research on the gene-environment interplay in relation to adolescent adjustment.

Geertjan Overbeek is Assistant Professor at the Department of Developmental Psychopathology, Radboud University Nijmegen the Netherlands. He obtained his Ph.D. in 2003 at the University of Utrecht. His primary research interests relate to the development of romantic partner relationships in late adolescence, and the linkages between parent-child relationships and social-emotional adjustment of youths.

Giovanni ten Brink is working at the Research Technical Support Center of the Radboud University Nijmegen. He is an expert on social relation analyses, and a software programmer for experimental designs.

Els Rommes is Assistant Professor Gender, ICT and Pedagogy at the Institute for Gender Studies, Radboud University Nijmegen. She received her Ph.D. in Gender and Science and Technology Studies at Twente University. Her research interests and main publication areas include gender scripts and the Internet, e-learning systems and pedagogy, gendered images of technology and teenagers' gendered professional choices. 
Raymond A. T. de Kemp Assistant Professor, received his Ph.D. in the Social Sciences from the Radboud University of Nijmegen, the Netherlands. Currently, his main areas of interest are juvenile delinquency, parenting and peer relations.

Luc Goossens is Full Professor in Developmental Psychology, Catholic University of Leuven, Belgium. He received his Ph.D. from the Catholic University of Leuven, Belgium, 1988. Current research interests include adolescent identity, autonomy, and loneliness.
Rutger C. M. E. Engels is Full Professor at Department of Developmental Psychopathology, Radboud University Nijmegen the Netherlands. He obtained his Ph.D. from the University of Maastricht in 1998. His primary research interests relate to the role of social influence processes in the development of problem behaviors in adolescence. Main topics of interest are social interaction processes, deviant behavior, parenting, addiction (e.g. alcohol abuse, smoking behavior, overeating), and peer relations. 